\title{
LA LEGITIMACIÓN EN DEMANDAS DE RESPONSABILIDAD AMBIENTAL. LAS ENSEÑANZAS DEL DERECHO GHILENO Y FRANCÉS*
}

\author{
LEGAL STANDING OF ENVIRONMENTAL LIABILITY CLAIMS. \\ CONTRIBUTIONS OF CHILEAN AND FRENCH LAW
}

\section{Pedro HARRIS MOYA**}

RESUMEN: La reciente consagración del perjuicio ecológico en el derecho francés plantea interrogantes ya solucionadas en el derecho chileno. No obstante, también permite interrogarse sobre la conveniencia de las soluciones aplicables en Chile. El régimen de legitimación frente a la reparación de daños ambientales es un ejemplo de ello. La legitimación activa del derecho francés es una enseñanza para el derecho chileno. Respecto de las soluciones adoptadas frente a la legitimación pasiva, esta apreciación se invierte.

Palabras claves: legitimación, daño ambiental, responsabilidad, reparación, ambiente.
ABSTRACT: The recent enactment of ecological damage in french law raises questions which have already been solved in chilean law. However, it also raises questions about the applicable solutions in Chile. The legal standing of claims for environmental damage is an example of this. Legal standing to sue in French law serves as an example for chilean law. However, regarding the ability to be sued, it is possible to come to the opposite conclusion.

Keyzerds: legal standing, environmental damage, liability, compensation, environment.

SUMARIO: I. Introducción. II. Las enseñanzas del derecho francés frente a la legitimación activa. III. Las enseñanzas del derecho chileno frente a la legitimación pasiva. IV. Conclusiones. V. Bibliografia.

* Recibido el 20 de febrero de 2020; aprobado el 17 de noviembre de 2020.

** ORCID: 0000-0002-4361-1739. Doctor en Derecho público de la Universidad de Paris 1, Panthéon-Sorbonne. Profesor de Derecho administrativo de la Universidad Autónoma de Chile, Santiago, Chile. Correo electrónico: pedro.harris@uautonoma.cl

Boletín Mexicano de Derecho Comparado, nueva serie, año LIII, núm. 158, mayo-agosto de 2020, pp. 733-761. 


\section{INTRODUCGIÓN}

Pese a las diferencias con las que Chile y Francia pueden abordar la función de protección del ambiente, su derecho se aproxima hoy en día en cuanto a las reglas aplicables en ciertos ámbitos, como en materia de responsabilidad ambiental. Actualmente ambos países poseen legislaciones especiales que especifican el régimen extracontractual. Aquellos que dañen o causen perjuicios a ciertos elementos ambientales, deberán desarrollar una reparación mediante reglas específicas. Ellas han sido consagradas en la Ley 19.300, Bases Generales del Medio Ambiente en Chile, y en la Ley del 8 de agosto de 2016, relativa a la reconquista de la biodiversidad en Francia. Cada una de estas legislaciones inciden en múltiples aspectos, como frente a la noción del daño o perjuicio, el plazo de prescripción o las formas de reparación. Contrario a lo que podría pensarse, las diferencias no son puramente sustantivas, sino también adjetivas. El acceso a la justicia en materia ambiental ha sido uno de los aspectos modificados en dichas leyes.

$\mathrm{El}$ acceso a la justicia presenta hoy en día una actualidad difícilmente cuestionable en materia de responsabilidad ambiental. El Estado no sólo es un garante para su protección, sino también un eventual autor que, directa o indirectamente, puede intervenir en la verificación del hecho generador o en su relación causal con el daño o perjuicio provocado. Todo ello explica que sus órganos intervengan como demandantes o demandados en los procesos de reparación en materia ambiental. Una situación similar ocurre respecto de particulares que, ya sea en tanto personas naturales o jurídicas, pueden intervenir ejerciendo un rol y otro. Aunque el acceso a la justicia ambiental "se relaciona con los medios para acudir a los tribunales” (Anglés 2017), la justicia ambiental como tal va más allá e integra también al demandado en un proceso judicial de reparación de daños o perjuicios. Ambas calidades se expresan a través de la legitimación que todos ellos deben poseer.

En efecto, tanto en el derecho chileno como en el francés, la constitución de una relación jurídica procesal supone diferentes condiciones. Estas podrán relacionarse con los órganos jurisdiccionales, las características del proceso o, en fin, las partes que intervienen en él. La noción de legitimación forma parte de este último aspecto. La legitimación es un presupuesto del proceso, referido a la persona que interpone una acción jurisdiccional (recibiendo en tal caso una calificación activa), o a aquella

Esta obra está bajo una Licencia Creative Commons

Atribución-NoComercial-SinDerivar 4.0 Internacional, IIJ-UNAM.

Boletín Mexicano de Derecho Comparado, núm. 158, mayo-agosto de 2020, pp. 733-761. 
en contra de quien se ejerce (siendo en este supuesto calificada de pasiva). Aunque la legislación ambiental en Chile se refiera expresamente a este concepto en su primera forma ${ }^{1}$, la doctrina recurre también a ella en esta última modalidad (Bordalí 2010, 234; Delgado 2012, 57). Una y otra noción son traducidas al francés por el empleo de categorías diversas. ${ }^{2}$ Cualquiera sea la noción aceptada, se referirá a exigencias que el demandante y el demandado deberán reunir para asegurar la constitución de la relación jurídico-procesal. El acceso a la justicia en materia de responsabilidad frente a daños ambientales no es una excepción a lo anterior.

A diferencia de lo que ocurre en otros ámbitos, el régimen de legitimación posee complejidades particulares en materia de responsabilidad ambiental. Desde un punto de vista activo, referido a la posición del demandante, éstas se explican por la carencia de subjetividad de los elementos ambientales, que requieren de legitimados que personifiquen su protección. Desde un punto de vista pasivo, referido a la posición del demandado, dichas complejidades se asocian a la responsabilidad que pudiere afectar a aquellos que dañen de manera significativa uno o más de sus componentes. La ausencia de una titularidad jurídica específica respecto del medioambiente puede suponer restricciones para imponer su reparación al autor, como resultado de la aplicación de ciertas nociones estructurales de la responsabilidad. Las relaciones entre ambas perspectivas, en el marco de un proceso judicial, justifican el análisis conjunto de ambas legitimaciones, frente a la reparación de daños ambientales. Y, para tales efectos, la comparación del derecho chileno y francés es particularmente útil, en términos temporales y materiales.

1 Mientras que el artículo 54 de la Ley 19.300, Bases Generales del Medio Ambiente, se refiere a los titulares de la acción ambiental, el artículo 20 de la Ley 20.600, que crea los tribunales ambientales, alude expresamente a la legitimación, en su variante activa.

2 En el derecho chileno el concepto de legitimación permite identificar las condiciones subjetivas que requiere el proceso, respecto del demandante (legitimación activa) y demandado (legitimación pasiva). Aunque el derecho francés carece de un término que permita traducirlo, diferentes nociones han sido propuestas. Es el caso de las expresiones de "calidad para actuar" — qualité à agir- (García de Enterría 2000, 101) y de "admisibilidad de la demanda" - recevabilité - (Esteban 2005). No obstante, la noción de legitimación sufre de ciertas variaciones en el derecho chileno, si se considera que, conforme a la posición mayoritaria de la doctrina, su determinación es una cuestión de fondo - bien fondé- de la acción. Contra esta interpretación, pero constatando su extensión (Bordalí 2018, 72). 
En términos temporales, la responsabilidad ambiental consagra diferencias significativas entre el derecho chileno y francés. Mientras que en el caso chileno este régimen remonta a 1994, con la dictación de la Ley 19.300; en el caso francés, éste posee una consagración reciente, con la Ley del 8 de agosto de 2016. La separación de más de veinte años entre ambas legislaciones únicamente se aproxima con la legislación francesa en materia de daño ambiental de $2008,{ }^{3}$ por la transposición de la Directiva 2004/35 del Parlamento Europeo y del Consejo, relativa a la responsabilidad medioambiental. Sin embargo, contrario a lo que podría pensarse, esta directiva no consagra un régimen de responsabilidad strictu sensu, sino un mecanismo preventivo y reparador de daños, aplicable a ciertas actividades, mediante el ejercicio de competencias de policía administrativa (Fuchs 2008).

En términos materiales, estas legislaciones en el derecho chileno y francés tienen también una naturaleza distinta. Por un lado, esto se aprecia en relación con su régimen jurídico. Mientras que la Ley chilena 19.300 consagra un sistema de responsabilidad en sentido estricto, la opción seguida por la Ley francesa del 8 de agosto de 2016 ha sido diversa. Sin consagrar una responsabilidad strictu sensu, ésta establece un mecanismo de reparación común a sus diferentes regímenes. Por otro lado, las diferencias se asocian a la calificación jurídica. Más allá de la distinción entre las nociones de daño y perjuicio, éstas se relacionan con los componentes afectados. La referencia al ambiente en el derecho chileno (que integra tanto elementos naturales, como socioculturales y sus interacciones) explica que la responsabilidad tenga un campo de aplicación extenso (Valenzuela 2010, 318; Ropert y Saavedra 2005) frente al derecho francés, ${ }^{4}$ referido al componente ecológico.

La separación temporal y material de estas legislaciones incide en el contenido de la protección ambiental consagrada en ambos casos. Las legislaciones relativas a la responsabilidad ambiental en el derecho chileno y francés suponen esfuerzos por adaptar las estructuras tradicionales del derecho de daños en este ámbito específico. Sin embargo, el carácter innovador que esta responsabilidad presenta llevará, necesariamente, a que cada régimen posea una identidad propia, con sus límites y aportes.

3 Ley del 1o. de agosto de 2008, relativa a la responsabilidad ambiental.

4 Artículo 2 letra ll) de la Ley chilena 19.300; artículo 1247 del Código Civil francés.

Esta obra está bajo una Licencia Creative Commons

Atribución-NoComercial-SinDerivar 4.0 Internacional, IIJ-UNAM.

Boletín Mexicano de Derecho Comparado, núm. 158, mayo-agosto de 2020, pp. 733-761. 
De manera tradicional, esta identidad sólo resulta apreciable por contraste con otros ordenamientos jurídicos que, en función de su alteridad, permitan desarrollar la función crítica y constructiva de la comparación (Gaudemet 1989, 905). Este es el resultado de abordar la noción de legitimación en relación con la responsabilidad ambiental en ambos países. En efecto, en el estado de la jurisprudencia actual, el derecho francés consagra enseñanzas relevantes para la legitimación activa frente al derecho chileno (II). Estas enseñanzas, no obstante, se invierten frente a la faz pasiva de la legitimación (III).

\section{LAS ENSEÑANZAS DEL DERECHO FRANCÉS FRENTE A LA LEGITIMACIÓN ACTIVA}

En la responsabilidad ambiental, la importancia de determinar la legitimación activa es evidente. Si el ambiente no es ni "una persona" ni bien "apropiado" como entidad (Camproux-Duffrene 2015), se impide que su representación se rija por las reglas generales, que ante la responsabilidad imponen, entre otras condiciones, la necesidad de acreditar el carácter "personal" del derecho o interés lesionado. Ello explica que el legislador haya determinado las condiciones que el legitimado debe poseer, integrando a algunos de ellos, aunque con variaciones significativas en ciertos casos. Estas se observan en las limitaciones de los intereses representados por las personas públicas (1) y privadas (2) frente a la responsabilidad ambiental en el derecho chileno, en contraste con aquellos reconocidos por parte del legislador francés.

\section{La legitimación activa de las personas públicas}

Las personas públicas no sólo son legitimadas pasivas frente a los daños causados al medioambiente, sino también, y sobre todo, son unos de sus principales legitimados activos. Así permite constatarlo la simple lectura del derecho chileno y francés. En ambos casos, existe un reconocimiento extenso de la intervención de las personas públicas, en representación de intereses generales. No obstante, diferentes variaciones existen frente a la amplitud con que esta representación es consagrada respecto de órganos que sólo representan una parte de estos intereses (A). Parale- 
lamente, una variación también existe frente a órganos que sustituyen la representación de ciertos intereses generales por otros, de una naturaleza colectiva (B).

\section{A. Los intereses generales}

La legitimación para demandar la reparación ambiental en el derecho chileno ha sido consagrada por el artículo 54 de la Ley 19.300, en favor de dos clases de personas públicas: tanto el Estado como las municipalidades. En principio, el otorgamiento de ambas titularidades se justifica por las funciones que son consagradas en su favor por otras disposiciones. En el caso del Estado, estas funciones tienen un valor constitucional, al ser éste el destinatario del deber de tutelar la preservación de la naturaleza (artículo 19, 8 de la Constitución Política de 1980), mientras que en el caso de las municipalidades, ellas se integran en sus competencias compartidas, establecidas por el artículo 4, letra b de la Ley 18.695, de Municipalidades, según el cual dichos órganos deben ejercer, entre otras actividades, la protección del ambiente. Cabe preguntarse, sin embargo, si dichas titularidades son representativas de los intereses involucrados frente al daño ambiental.

Las limitaciones se relacionan con el carácter restrictivo que posee la competencia de los órganos públicos para ser legitimados activos en el ejercicio de la acción de reparación del daño ambiental (Tisné 2014, 341). Más allá de la competencia reconocida al Estado, el artículo 54 de la Ley 19.300 sólo le reconoce a las municipalidades el ejercicio de esta acción. No obstante, las municipalidades únicamente integran una forma específica de organización administrativa territorial, existente en el ámbito comunal o local. Contrario sensu, esto caracteriza el rechazo de otras legitimaciones frente a órganos que ejercen competencias en una escala diversa, como la región y provincia, cuya administración ha sido objeto de reformas recientes del derecho chileno. ${ }^{5}$ Asimismo, dicha consagración supone negar la legitimación que otros órganos pueden ejercer, no con base al territorio, sino a sus funciones, lo que en el derecho chileno resulta imperativo, por la aplicación de disposiciones favorables a la descentrali-

5 Véase, entre otras, la Ley 21.073, que permite la elección democrática del gobernador regional y la Ley 21.074, sobre el fortalecimiento de la regionalización del país. 
zación territorial y funcional, consagradas en el artículo 3 de la Constitución de 1980.

La legitimación activa de los órganos públicos en el derecho francés contrasta con esta situación. Para que una persona sea parte activa en el proceso, el artículo 1248 del Código Civil francés sólo requiere de una calidad y de un interés. Esto se explica por la preferencia del legislador de una enumeración no exhaustiva (Neyret 2017), descartando así la propuesta inicial, favorable a una lista taxativa de legitimados (Jégouzo 2013, 24). Respecto de las personas públicas, ésta es la primera diferencia con el derecho chileno, en donde la enumeración es exhaustiva, ${ }^{6}$ como resultado de la expresión "son titulares de la acción" que, pese a ser utilizada en el artículo 54 de la Ley 19.300, resulta difícil de conciliar en materia de derechos constitucionales (Bordalí 2010, 233). Un segundo aspecto se relaciona con la extensión de esta enumeración. Los cuatro primeros titulares de la acción de reparación del perjuicio ecológico en el derecho francés tienen una personalidad pública. Todos ellos corresponden tanto al Estado, como a la Agencia francesa en materia de Biodiversidad, a las colectividades territoriales y a los establecimientos públicos.

Lo anterior tiene incidencia respecto a los intereses que son representados en el proceso. En efecto, cada una de estas personas de derecho público se estructuran, en el derecho francés, según una forma de organización administrativa diversa, lo que se manifiesta en sus intereses para demandar la reparación del perjuicio. "El principal obstáculo al ejercicio de la acción civil por parte de personas jurídicas de derecho público distintas del Estado consiste en que la generalidad de sus competencias tiene por efecto confundir sus intereses con el interés general, cuya protección incumbe sólo al Ministerio Público" (Huten y Dumont 2008, 210). La característica del artículo 1248 del Código Civil francés es distinguir diferentes titularidades. Si bien todo interés general es representado por el Estado, la Agencia francesa para la Biodiversidad, las colectividades territoriales y los establecimientos públicos pueden representar, ya sea un interés general determinado, ya un interés colectivo.

6 Sentencia de Corte Suprema del 16 de octubre de 2017, rol: 62208-2016. 


\section{B. Los intereses colectivos}

En el derecho chileno, las limitaciones de la representación de los intereses colectivos se relacionan con la competencia municipal. Su legitimación para demandar la reparación ambiental se limita en contraste con aquella consagrada en favor del Estado. En algunos casos, la Ley 19.300 condiciona la facultad del municipio respecto de los "hechos acaecidos en sus respectivas comunas" (artículo 54 inciso 1), mientras que en otros ella requiere que las actividades que causan daño ambiental "se desarrollen" en ella (artículo 54 inciso 2). A partir de cada una de estas expresiones, el legislador chileno parece haber reiterado, respecto de la persona pública municipal, el carácter personal del daño, exigido en materia de responsabilidad extracontractual civil. No obstante, las fórmulas utilizadas acarrean una serie de inconvenientes, si se considera que los hechos "acaecidos" y las actividades "desarrolladas" pueden hacer alusión a dos lugares en rigor diversos.

En efecto, una característica de la causalidad en materia de responsabilidad ambiental se asocia a las distancias que pueden existir entre el lugar en el que se origina el hecho generador del daño y aquel en el que éste se manifiesta. Sólo una interpretación amplia de los hechos "acaecidos" puede entenderse en relación con cada uno de estos lugares, permitiendo solucionar los problemas de legitimación que supondría un hecho originado en una comuna, que causa daño en otra. ${ }^{7}$ El segundo supuesto, en cambio, presenta mayores complejidades, al referirse a actividades "desarrolladas" en la comuna respectiva. Esta referencia sólo puede entenderse en relación con el lugar en el que se origina el hecho que causa daño, descartando aquél en el cual éste se manifiesta. Esta limitación puede ser cuestionable si se considera que, en este supuesto, la municipalidad no podrá representar el interés colectivo de sus propios habitantes. Este cuestionamiento se agrava considerando que, como se verá, esta acción tiene un carácter residual, siendo invocable por todos aquellos que carecen de una legitimación expresa en la ley.

La característica del artículo 1248 del Código Civil francés, en relación con este aspecto, se asocia a la amplitud con que es reconocida la le-

7 Sentencia del Tercer Tribunal Ambiental del 28 de diciembre de 2017, rol: D-172016, cons. 7-10.

Esta obra está bajo una Licencia Creative Commons

Atribución-NoComercial-SinDerivar 4.0 Internacional, IIJ-UNAM.

Boletín Mexicano de Derecho Comparado, núm. 158, mayo-agosto de 2020, pp. 733-761. 
gitimación activa de ciertos órganos dotados de una competencia territorial. A diferencia del derecho chileno, la legitimación activa para ser parte en el proceso no asocia a un órgano de naturaleza determinada (como ocurre frente a las municipalidades), sino a un concepto genérico, susceptible de integrar diferentes órganos, agrupados en torno al concepto de colectividad territorial. Esto se explica porque en el derecho francés la colectividad territorial no sólo integra al municipio, sino también a las regiones, a los departamentos, a las colectividades con estatutos especiales, e incluso, a administraciones ubicadas más allá del territorio continental. Todos estos órganos públicos se encuentran legitimados para demandar la reparación del perjuicio ecológico.

Paralelamente, la extensión de la legitimación activa, respecto de colectividades territoriales en el derecho francés, debe entenderse asociada a las características de su intervención en procesos de reparación en materia ambiental. Según el órgano de que se trate, el artículo 1248 del Código Civil francés no consagrará, necesariamente, la atribución de una legitimación original, sino eventualmente una adaptación de ella, frente a otras disposiciones que habilitaran para demandar otros perjuicios. Este es el caso de las colectividades territoriales, cuya legitimación ya era reconocida con anterioridad a esta ley, permitiendo su intervención en casos emblemáticos, como el Affaire Erika. ${ }^{8}$ No obstante lo anterior, se trataba de un reconocimiento legal previsto en términos restrictivos, que limitaban su competencia respecto a los hechos ocurridos únicamente en su territorio, aproximándose así a la fórmula empleada en el derecho chileno. La Ley francesa del 8 de agosto de 2016, relativiza el empleo de esta expresión, permitiendo con ello extender sus facultades. ${ }^{9}$

Notemos, en último término, que la legitimación del artículo 1248 del Código Civil francés se enmarca en un régimen de reparación que, pese a ser consagrado en dicho Código, introduce variaciones al rol de las personas jurídicas de derecho público. La carencia de reconocimiento de la reparación del perjuicio ecológico, unido a la exigencia de un perjui-

8 Sentencia de la Corte de Casación (sala criminal) del 25 de septiembre de 2012, 3439.

9 El artículo L. 142-4 del Código del Medioambiente francés permite que las colectividades territoriales demanden los "perjuicios directos o indirectos del territorio sobre el cual ejercen sus competencias". En cambio, el artículo 1248 del Código Civil francés permite que las colectividades territoriales demanden la reparación del perjuicio ecológico del territorio "concernido". 
cio personal, para hacer exigible la responsabilidad, había llevado a que, tradicionalmente, las personas jurídicas de derecho público intervinieran en estos procesos a través de la invocación del perjuicio material o moral que les había ocasionado, indirectamente, el daño ambiental (Nesi 2012). Si bien esta técnica no debe entenderse abandonada a partir de la entrada en vigor de la Ley francesa del 8 de agosto de 2016, a partir de ella las personas jurídicas de derecho público ostentan una legitimación activa diversa, lo que también incide en favor de la intervención como demandantes de las personas privadas en este ámbito.

\section{La legitimación activa de las personas privadas}

No parece posible negar que la enumeración de legitimaciones activas en el derecho chileno y francés, respecto de la reparación ambiental, otorgue un rol protagónico a las personas públicas. En ambos países ellas comprenden la mayor parte de la enumeración de demandantes. Dicha extensión, sin embargo, no ignora que las personas privadas puedan tener un rol trascendente como legitimados activos, en mayor o menor medida en ambos casos. En particular, respecto de las acciones ejercidas por asociaciones de protección medioambiental. Todo ello permite que un país y otro integren a las personas privadas, bajo una geometría variable. Así, en el derecho chileno esta atribución no es aceptada unánimemente frente a personas naturales (A), sin perjuicio que sea reconocida en beneficio de determinadas personas jurídicas (B). Ambos aspectos se extienden en el derecho francés.

\section{A. Los intereses individuales}

El ejercicio de acciones por personas privadas, frente a las demandas de responsabilidad ambiental, ha sido limitada en el derecho chileno. Esto se explica porque esta legitimación requiere que las personas "hayan sufrido el daño o perjuicio". Para un sector de la doctrina, la lesión referida por esta disposición sería próxima al perjuicio civil (Barros 2006, 810 y $811),{ }^{10}$ lo que resulta fundado si se considera que el legislador, primero,

10 Véase Sentencia de la Corte Suprema del 16 de octubre de 2017, rol: 62208-2016, cons. 7. No obstante, una interpretación diversa ha sido seguida por algunos tribunales 
asimila el daño a un perjuicio (por el empleo de la preposición "o"), abandonando la relación de causa a efecto que estas nociones implican (Sousse 1994, 374), y segundo, requiere que el ejercicio se realice por el "directamente afectado" (Tisné 2014, 334). En todo otro caso, deberá recurrirse al inciso 2 de esta disposición, conforme al cual: "Cualquier persona podrá requerir a la municipalidad en cuyo ámbito se desarrollen las actividades que causen daño al medio ambiente para que ésta, en su representación y sobre la base de los antecedentes que el requirente deberá proporcionarle, deduzca la respectiva acción ambiental".

Por ello, la primera limitación se origina por el alcance del artículo 54 inciso 2 de la Ley 19.300. No deben ignorarse las dificultades de interpretación que inicialmente presentó esta disposición. Especialmente, ante la aparente contradicción que existiría entre una referencia a "cualquier persona" y la competencia de la "municipalidad en cuyo ámbito se desarrollen las actividades que causen daño al medio ambiente". Esta aparente contradicción llevó a que un sector de la doctrina calificara dicha disposición en términos de una acción pública en materia ambiental, que en estricto rigor haría innecesario recurrir a otras legitimaciones (Vidal 2007, 130). Tal interpretación ignoró que el artículo 54 inciso 2 de la Ley 19.300 se limita a consagrar un simple interés en favor de una persona para iniciar la tramitación de un procedimiento administrativo municipal. Por ello, la legitimación activa no es consagrada a favor del solicitante, sino de la municipalidad, quien puede rechazar su ejercicio, debiendo sin embargo comunicar su intención de no ejercer la acción de reparación. ${ }^{11}$

Esta técnica legislativa contrasta con el derecho francés. Teóricamente, las acciones jurisdiccionales en materia de responsabilidad ambiental pueden supeditarse a la lesión de derechos o intereses. Y, en la práctica, ambas formas de legitimación activa son admisibles en Francia. Por un lado, ya que el artículo 1o. de la Carta del Medio Ambiente (que posee valor constitucional, desde la adopción de la ley del 1o. de marzo de 2005) reconoce derechos en favor de toda persona, siendo interpretada extensi-

de fondo: Sentencia del Segundo Tribunal Ambiental del 20 de marzo de 2015, rol: D-22013; Sentencia del Segundo Tribunal Ambiental del 31 de julio de 2017, rol: D-28-2016. Véase también: Sentencia del Tercer Tribunal Ambiental del 31 de diciembre de 2018, rol: D-7-2015.

11 Artículo 54 inciso 2 de la Ley 19.300. Véase: Delgado 2012, 64. 
vamente por la Corte Constitucional francesa. ${ }^{12}$ Y, por otro lado, debido a que los componentes medioambientales (o, al menos, aquellos susceptibles de integrarse en tanto componentes "ecológicos", referidos por el legislador francés en este ámbito) han sido calificados de interés general. ${ }^{13}$ Esto es coherente con la jurisprudencia, al ser la vulneración de derechos e intereses susceptible de reparación. Así se infiere del concepto de perjuicio, definido como "una lesión de un derecho o de un interés protegido por la ley” (Camproux-Duffrene y Guihal 2013).

Por ello, la condición exigida por el legislador francés para otorgar la legitimación activa constituye una extensión frente al derecho chileno. A diferencia de este último, la Ley francesa del 8 de agosto de 2016 ha abandonado la exigencia de un "derecho" lesionado, permitiendo que un simple interés otorgue legitimación. La cuestión estará vinculada a la entidad del interés. En rigor, el interés es una exigencia siempre necesaria, cualquiera que sea la persona que demande la reparación del perjuicio ecológico. No obstante, su forma concreta no debe confundirse con este último concepto (Gueye 2016, 286), sin perjuicio de la relación que exista entre uno y otro, reflejada en ocasiones en la reducción de los montos de indemnización del perjuicio. Esta distinción es relevante para analizar algunas posiciones, como aquella del Consejo de Estado francés que, como se verá, limita la responsabilidad ambiental frente a la administración, ante el ejercicio de acciones por asociaciones de protección.

\section{B. Los intereses asociativos}

Las limitaciones a la representación de intereses individuales, en demandas de responsabilidad ambiental en el derecho chileno, se reiteran frente a intereses asociativos. En tanto personas jurídicas privadas, las asociaciones de protección ambiental carecen de una disposición especial que les otorgue una legitimación activa específica. Cierto, ellas pueden intervenir en el proceso conforme al procedimiento general consagrado

12 Sentencia del Consejo Constitucional del 8 de abril de 2011, 2011-116.

13 Entre otros: artículo 1o. de la ley del 10 de julio de 1976, respecto de la naturaleza; artículo 4o. de la ley del 2 de mayo de 1930, respecto de monumentos naturales; artículo 55 de la ley del 9 de enero de 1985, respecto de la montaña. Véase en este sentido Prieur (2011, 63 y 64). 
en el artículo 54 inciso 2 de la Ley 19.300, que permite solicitar la representación del municipio. No obstante, los límites de esta vía han llevado a que dichas organizaciones sustituyan esta invocación por la legitimación general otorgada por el inciso 1 de esta norma, referida a las "personas naturales o jurídicas, públicas o privadas, que hayan sufrido el daño o perjuicio". Ya se ha señalado que este artículo requiere acreditar el perjuicio frente a personas naturales. No obstante, se discute si "el daño o perjuicio" ambiental puede entenderse implícito en aquel que pueden sufrir ciertas entidades y personas jurídicas.

La posibilidad que entidades no personificadas puedan ejercer la acción de responsabilidad por el daño ambiental, conforme al artículo 54 de la Ley 19.300, no resulta aceptable en función de su interpretación literal. Pese a que la consagración de la responsabilidad ambiental tuvo por objeto disociar el daño al ambiente de su carácter "personal", el legislador chileno condicionó esta intervención al otorgamiento de una personalidad, respecto de aquellos que estuvieren legitimados. En contraste, una opción diversa ha sido afirmada frente a la responsabilidad civil extracontractual general, donde un sector de la doctrina parece reconocer esta intervención como parte activa (Larrain 2011, 176 y 177). La admisibilidad del ejercicio de esta clase de acciones es ciertamente reducida frente a la responsabilidad ambiental, si se considera que la jurisdicción analiza, de manera invariable, tanto la existencia de la persona jurídica como también sus condiciones de validez. ${ }^{14}$

Algo distinto sucede respecto de entidades personificadas. Aunque un sector de la doctrina ha negado su titularidad frente a estas acciones (Barros 2006, 810 y 811), la jurisprudencia ha sido favorable al ejercicio demandas de responsabilidad ambiental. No obstante, sin que exista claridad acerca de las condiciones que debe reunir. Si bien algunas sentencias favorecen un análisis formal, que consiste en una revisión del objeto social, ${ }^{15}$ la jurisprudencia no ha descartado abiertamente un análisis material, aplicable por regla general a personas naturales y a otras personas jurídicas, por medio de la aplicación de la teoría del entorno adyacente, ${ }^{16}$ que condiciona la legitimación activa a la afectación que el daño supone

\footnotetext{
14 Sentencia del Segundo Tribunal Ambiental del 20 de marzo de 2015, rol: D-2-2013.

15 Ibidem, cons. $23^{\circ}$.

16 Ibidem, cons. $15^{\circ}$.
} 
(Bermúdez 2007, 81-86). Esta teoría, que ha sido formulada en materia de garantías constitucionales, permite determinar en qué medida la afectación coincidiría con los efectos del daño ambiental, impidiendo que la distancia sea un obstáculo a la legitimación. No obstante, su aplicación no ha estado exenta de críticas, por la dificultad de concretar tal noción, tanto en términos generales (Galdámez 2017, 132-133), como específicos, referidos a las asociaciones de protección (Tisné 2016, 250).

Ello contrasta con la liberalidad del derecho francés, donde la extensión de este aspecto es característico. La consagración de una legitimación activa respecto de asociaciones de protección ambiental no es una innovación de la Ley francesa del 8 de agosto de 2016. Estas asociaciones han sido legitimadas en esta materia, ya desde la Ley Barnier del 2 de febrero de 1995, a partir de disposiciones inicialmente referidas al proceso penal, pero cuya aplicación fue aceptada por la jurisprudencia francesa en otros ámbitos, como es el caso de la reparación de perjuicios civiles (Boutonnet 2010, 93). ${ }^{17}$ La técnica para desarrollar esta legitimación ha consistido en reconocer, a favor de estas asociaciones de protección, la reparación del perjuicio moral que un daño ambiental les ocasiona, de integrarse en los objetivos referidos en sus estatutos sociales. Ello explica que, a diferencia del derecho chileno, la intervención de dichas asociaciones haya sido protagónica (Calmette 2008, 269), tanto en la jurisdicción administrativa como judicial.

Ahora bien, la sola circunstancia que las asociaciones de protección ambiental ya contaran con una legitimación tradicional frente a la reparación de estos daños no implica, necesariamente, que la Ley francesa del 8 de agosto de 2016 carezca de toda utilidad al respecto. El legislador francés ha reconocido la legitimación activa de asociaciones autorizadas, cuya calidad e interés ya eran objeto de una jurisprudencia constante, tanto judicial como administrativa. Sin embargo, la ley reconoce también esta legitimación en favor de asociaciones que carecen de un régimen específico, conocido como agréement, a condición de que existan durante cinco años antes de la interposición de la demanda. El régimen de agréement refuerza la intervención de las asociaciones de protección ambiental, al otorgarles una presunción de interés (Léost 1995, 277), que permitiría su-

17 Véase Sentencia de la Corte de Casación (Segunda Sala Civil) del 7 de diciembre de 2006, 05-20297.

Esta obra está bajo una Licencia Creative Commons

Atribución-NoComercial-SinDerivar 4.0 Internacional, IIJ-UNAM.

Boletín Mexicano de Derecho Comparado, núm. 158, mayo-agosto de 2020, pp. 733-761. 
perar el carácter casuístico de su análisis en el derecho chileno. Sin embargo, no es un obstáculo respecto de asociaciones que carecen de él, por el reconocimiento legal de una posición próxima a aquella afirmada por la jurisprudencia judicial (Neyret 2017). ${ }^{18}$

Un último aspecto destacable de la legitimación activa de estas asociaciones en el derecho francés se relaciona con la interpretación de su interés. Es sabido que el interés de las asociaciones de protección ambiental ha sido reconocido con un cierto grado de liberalidad por la jurisprudencia francesa, a diferencia del derecho chileno, donde los tribunales ambientales sólo recientemente han acogido acciones de reparación ambiental ejercidas exclusivamente por ellas. ${ }^{19}$ Sin embargo, es posible interrogarse si este reconocimiento ha sido reforzado con la Ley francesa del 8 de agosto de 2016. Antes, la doctrina destacaba cómo la apertura del interés era controlada por los montos de las reparaciones de perjuicios morales, desplazando la discusión desde la admisibilidad de la demanda al éxito de la acción (Thévenot 1994). Hoy, la acción de reparación ambiental es diversa de aquella destinada a obtener dicha indemnización, impidiendo que el juez recurra a esta técnica. La sola limitación deriva de la circunstancia de haberse causado un perjuicio no insignificante, ${ }^{20}$ lo que habilitará para accionar en contra del legitimado pasivo.

\section{LAS ENSEÑANZAS DEL DERECHO CHILENO FRENTE A LA LEGITIMACIÓN PASIVA}

Las enseñanzas del derecho francés frente a la legitimación activa en materia de responsabilidad ambiental sufren limitaciones, por contraste con el derecho chileno, ante la legitimación pasiva. Diferentes razones podrían explicar esta constatación. Prima facie, éstas podrían asociarse a aspectos procesales, como el rol del juez y, más específicamente, a su carácter unitario (propio del derecho chileno) o dual (propio del derecho francés). ${ }^{21}$ Sin

18 En relación con la Sentencia de Corte de Casación (Tercera Sala Civil) del 26 de septiembre de 2007, 04-20.636.

19 Sentencia del Tercer Tribunal Ambiental del 30 de noviembre de 2017, rol: D-242017.

20 Artículo 1247 del Código Civil francés.

21 El derecho chileno carece de una referencia constitucional acerca de su modelo unitario o dual de conformación judicial. Esto ha permitido que algunos autores califiquen

Esta obra está bajo una Licencia Creative Commons Atribución-NoComercial-SinDerivar 4.0 Internacional, IIJ-UNAM. Boletín Mexicano de Derecho Comparado, núm. 158, mayo-agosto de 2020, pp. 733-761. 
embargo, cada uno de estos ordenamientos jurídicos consagran también diferencias sustantivas. Éstas preexisten a la responsabilidad ambiental, y se enmarcan en el ámbito de las reglas comunes aplicables. Por contraste con el derecho francés, todos estos elementos permiten que la legitimación pasiva de personas públicas (1) y privadas (2) sea más amplia en Chile.

\section{La legitimación pasiva de las personas públicas}

Sin perjuicio de las diferencias esenciales de la legitimación activa de las personas privadas, las diferencias contingentes entre el derecho chileno y el derecho francés recaen en la legitimación pasiva de las personas públicas. Los fundamentos normativos para aplicar el régimen de responsabilidad ambiental contra ellas son compartidos en ambos países. Primero, porque en un caso y otro esta responsabilidad carece de destinatario específico, al ser referida a "toda" persona. ${ }^{22} \mathrm{Y}$ segundo, ya que, aun cuando así no fuera, es evidente que las formas de reparación en este ámbito son específicas, siendo por ello necesaria su aplicación. No obstante, la jurisprudencia administrativa francesa conserva una lectura restrictiva, caracterizada por inaplicar este régimen (A). El contraste con el derecho chileno es significativo, al introducir modificaciones que afectan no sólo la reparación, sino también la responsabilidad $(\mathbf{B})$.

\section{A. La reparación ambiental}

Así como en el derecho chileno el daño ambiental no se confunde con sus efectos civiles, así también en el derecho francés el perjuicio ecológico se distingue de aquellos. Esta separación, en apariencia estrictamente conceptual, tiene efectos significativos en el proceso. Únicamente si el juez accede a reconocer el daño ambiental será posible que éste sea repara-

el régimen como hiperespecializado, frente al surgimiento de ciertos tribunales en ámbitos específicos, como ocurre en materia ambiental (Vergara 2017, 138). Por contraste, en el derecho francés este reconocimiento tiene un valor constitucional (Sentencia del Consejo Constitucional del 22 de julio de 1980, 80-119 y Sentencia del Consejo Constitucional del 3 de enero de 1987, 86-224), reflejado el modelo dualista de jurisdicción, que separa a los tribunales administrativos de los judiciales.

22 Véase artículo 51 de la Ley 19.300; artículo 1246 del Código Civil francés.

Esta obra está bajo una Licencia Creative Commons

Atribución-NoComercial-SinDerivar 4.0 Internacional, IIJ-UNAM.

Boletín Mexicano de Derecho Comparado, núm. 158, mayo-agosto de 2020, pp. 733-761. 
ble, con independencia de los perjuicios que se sigan respecto de ciertas personas y sus bienes. A diferencia de lo que ocurre en relación con los privados, la posición tradicional del derecho francés frente a las personas públicas ha sido contraria a esta interpretación. Se trata de una solución que remonta a la Decisión del Consejo de Estado francés del 12 de julio de 1969, Ville de Saint-Quentin, 72068. En la especie, con ocasión de una contaminación de aguas, el juez administrativo reconocerá que las federaciones de pescadores de la zona tenían derecho a la reparación de los perjuicios. No obstante, rechazará una indemnización a favor de las "pérdidas de la riqueza biológica de las aguas, que no pueden por sí mismas abrir derecho a la reparación", siendo sólo eventuales.

Pese a ser adoptada con anterioridad a la consagración de las principales legislaciones ambientales en el derecho francés (Deguergue 2017, 37), la decisión Ville de Saint-Quentin no será aislada. Al contrario, ella marcará una posición que será reiterada posteriormente por parte del Consejo de Estado, ${ }^{23}$ rechazando toda indemnización de los efectos dañosos sobre el ambiente, en caso de ser disociados de un perjuicio personal. El reconocimiento del perjuicio ecológico por el artículo 1246 del Código Civil francés tiene precisamente este objeto. De aquí que los autores se interroguen acerca de su aceptación por parte del juez administrativo francés. Pese a que la doctrina sea favorable a esta aplicación (Neyret 2017; Huglo 2016), e incluso la califiquen como "inevitable" en el tiempo (Huglo 2013), debe constatarse que esta reparación no ha sido reconocida en términos expresos, y que su consagración civil puede servir de límite a una aplicación integral en el derecho administrativo, considerando que la responsabilidad administrativa se funda en su adaptación.

De manera similar, la aplicación de este régimen de responsabilidad a la administración no ha sido pacífica en el derecho chileno. Si bien dicha aplicación ha sido defendida por un sector de la doctrina (Femenías 2017, 253), algunos autores han rechazado esta extensión, al suponer un régimen común, en circunstancias que la Administración debiera responder conforme a sus propias reglas (Bermúdez 2002, 263). ${ }^{24}$ Aunque esta

23 Sentencia del Consejo de Estado del 26 de octubre 1984, Fédération des associations de pêche et de pisciculture de la Somme y del 13 de noviembre de 2009, Association La Sauvegarde de la Moine, 310038.

24 Una lectura contraria ha sido defendida por el mismo autor. Véase Bermúdez (2007, 229). 
lectura tiene respaldo en el artículo 51 inciso 2 Ley 19.300 (que si bien contempla una aplicación básica de sus reglas, afirma una vigencia supletoria en caso que otras leyes consagren regímenes especiales de responsabilidad ambiental), ha retrocedido en favor de una interpretación diversa. Ello se explica por factores compartidos con el derecho francés (como la indistinción del autor del daño), pero también otros particulares, como su forma de consagración. A diferencia del régimen francés, el legislador chileno no recurrió al derecho civil para consagrar esta responsabilidad, dictando una ley de "bases generales". ${ }^{25}$

Por ello, la extensión del derecho chileno, frente a la legitimación pasiva por el daño ambiental, recae en la consolidación de esta nueva lectura en la jurisprudencia. Dicha consolidación ha sido progresiva. Inicialmente, los tribunales chilenos asociaban las diferentes legislaciones aplicables, tanto en materia administrativa como en el ámbito medioambiental, originando la combinación de la responsabilidad de la administración con el régimen de daños en materia ambiental. ${ }^{26}$ Esta articulación podría permitir un resultado similar al que, en rigor, tendría lugar en el derecho francés, frente al reconocimiento del perjuicio ecológico por parte del Consejo de Estado, permitiendo articular en el derecho chileno los fundamentos de la responsabilidad de la administración, con base al régimen de falta de servicio, y las funciones de la responsabilidad por el daño ambiental, que habilitan para reparar sus efectos bajo la Ley 19.300. No obstante, esta interpretación variará progresivamente, afectando al régimen de responsabilidad aplicable.

\section{B. La responsabilidad ambiental}

En rigor, el sólo reconocimiento de la reparación del perjuicio ecológico no permite superar las interrogantes sobre la aplicabilidad del régimen en contra de personas públicas, incluso en el evento de ser aplicado por el juez administrativo francés. En contraste con el derecho chileno, estas interrogantes se asocian al régimen de responsabilidad. Debe recodarse que, a diferencia de la Ley 19.300, la Ley francesa del 8 de agosto de 2016, no consagra un régimen de responsabilidad, sino de reparación, por

25 Artículo 63-20 de la Constitución de 1980.

26 Sentencia de la Corte Suprema del 30 de mayo de 2007, rol: 3174-2005.

Esta obra está bajo una Licencia Creative Commons

Atribución-NoComercial-SinDerivar 4.0 Internacional, IIJ-UNAM.

Boletín Mexicano de Derecho Comparado, núm. 158, mayo-agosto de 2020, pp. 733-761. 
lo cual los regímenes especiales de responsabilidad administrativa siguen siendo aplicables, incluso respecto de actividades susceptibles de provocar un perjuicio ecológico. Aunque estos regímenes pueden imponer una agravación de la responsabilidad aplicable en el derecho chileno, ${ }^{27}$ también pueden presentar ciertas restricciones susceptibles de dificultar su aplicación.

En el derecho francés esto se explica ya que, si bien el régimen de responsabilidad de la administración resulta heterogéneo, una homogeneidad existe en ciertos sectores. Con excepción de las hipótesis en que la administración intervenga activamente en la generación del perjuicio, éste será el caso de la actividad de protección ambiental. Tradicionalmente, la protección del medio ambiente en el derecho francés es interpretada como una intervención de policía especial (Jégouzo 2004, 24 y 25), caracterizada por una naturaleza técnica que agrava las exigencias de la responsabilidad. Respecto del régimen subjetivo, esta agravación podrá traducirse en la exigencia de falta grave o lata, aún afirmada por un sector de la doctrina (Eveillard 2006; Eveno 2003, 246). ${ }^{28}$ Inevitablemente, la traducción de dicha posición en este ámbito implicará una limitación de la Ley francesa del 8 de agosto de 2016, pues la reparación del perjuicio ecológico no depende sólo de su reconocimiento por el legislador, sino también de su extensión judicial.

Frente a esta constatación, cabe preguntarse la conveniencia de la solución del derecho chileno, al sustituir integralmente, no sólo las formas de reparación ambiental, sino también el régimen de responsabilidad de la administración. Este tránsito tuvo lugar por la prevalencia otorgada a los artículos 51 y siguientes de la Ley 19.300, que consagra una responsabilidad por culpa en materia ambiental, por sobre disposiciones generales, que establecen un régimen de responsabilidad por falta de servicio de la administración. ${ }^{29}$ Podría pensarse que la inaplicación de ciertos cuerpos

27 Esto es posible si se considera la posición favorable a la responsabilidad subjetiva en el derecho chileno, que requiere la prueba de la falta de servicio La doctrina francesa ya ha destacado la aptitud que ciertos regímenes ante riesgos ambientales; por ejemplo, el régimen de trabajos públicos y hospitalario (Deguergue 2000, 108).

28 Sentencia del Consejo de Estado del 10 de febrero de 1905, Tomaso Grecco.

29 El régimen de falta de servicio ha sido consagrado, tanto en términos generales (artículo 42 de la Ley 18.575, Bases Generales de la Administración del Estado; artículo 152 de la Ley 18.695, de Municipalidades), y en ciertas actividades específicas (artículo 38 de 
legales en beneficio de otros no tendría trascendencia, por su proximidad, al referirse a sistemas subjetivos de responsabilidad. Esta interpretación, que no es sostenida por toda la jurisprudencia, ${ }^{30}$ sin embargo, se limita frente a la interpretación de la doctrina, que rechaza la división tripartita de la culpa en el régimen de responsabilidad civil extracontractual (Ramos 1999, 250; Abeliuk 2001, 122-123), interpretación que es aplicada por los autores frente al daño ambiental (Astorga 2014, 442). Esto, unido a una extensa presunción de culpa ante la infracción de las disposiciones aplicables,${ }^{31}$ impide que la culpa condicione la responsabilidad en ámbitos técnicos, e incide también respecto de personas privadas.

\section{La legitimación pasiva de las personas privadas}

El que por regla general la persona pública ejerza la vigilancia de las actividades desarrolladas por personas privadas en materia ambiental no basta para prescindir de su responsabilidad. Razonar de otra forma llevaría, no sólo a carecer de la intervención que ellas tienen en el hecho generador, sino también a exceder los límites de la responsabilidad administrativa. En consecuencia, será necesario analizar la legitimación que se le otorga a las personas privadas. Diferentes razones llevan a afirmar que ellas, en el derecho francés, sufren de limitaciones por contraste con el derecho chileno. Así se observa frente al daño ambiental, en las hipótesis de pluralidad de autores (A) y de causas (B) intervinientes.

la Ley 19.966, que establece el régimen de garantías de salud). Aunque un sector de la doctrina interpreta que éste sólo procedería en supuestos de omisión (Soto Kloss 2012, 845), esta lectura no ha sido seguida por la Corte Suprema, al aplicar la exigencia de culpa, en los términos de la legislación ambiental.

30 Sentencia de la Corte Suprema del 5 de marzo de 2008, rol: 6346-2006.

31 Conforme al artículo 52 de la Ley 19.300: "Se presume legalmente la responsabilidad del autor del daño ambiental, si existe infracción a las normas de calidad ambiental, a las normas de emisiones, a los planes de prevención o de descontaminación, a las regulaciones especiales para los casos de emergencia ambiental o a las normas sobre protección, preservación o conservación ambientales, establecidas en la presente ley o en otras disposiciones legales o reglamentarias.

Con todo, sólo habrá lugar a la indemnización, en este evento, si se acreditare relación de causa a efecto entre la infracción y el daño producido".

Esta obra está bajo una Licencia Creative Commons

Atribución-NoComercial-SinDerivar 4.0 Internacional, IIJ-UNAM.

Boletín Mexicano de Derecho Comparado, núm. 158, mayo-agosto de 2020, pp. 733-761. 


\section{A. El concurso de autores}

Como se ha señalado, la Ley francesa del 8 de agosto de 2016 no consagra un régimen de responsabilidad strictu sensu, aplicable al autor de un perjuicio ecológico. Así se desprende de las disposiciones de apertura del régimen. Y, en particular, del artículo 1246 del Código Civil francés, conforme al cual: "toda persona responsable de un perjuicio ecológico es obligada a su reparación”. Como se observa, esta disposición parte de una responsabilidad acreditada en su contra. Por ello, este artículo reenvía a los múltiples regímenes de responsabilidad del derecho francés. Respecto de personas privadas, ellos guardan cierta armonía con el derecho chileno, como lo demuestra su influencia de su proceso de codificación (Díaz 2007, 83). Una vez que esta responsabilidad sea acreditada según cada régimen, el autor del perjuicio deberá repararlo con base en los artículos 1246 y siguientes del Código Civil. Así, la opción seguida por el legislador francés ha permitido consagrar esta reparación, limitando ciertas perturbaciones al régimen de responsabilidad.

La finalidad de evitar las perturbaciones del régimen de responsabilidad, sin embargo, debe ser compatibilizada con la eficacia de esta reparación. Y, en especial, con las garantías que son aplicables en esta materia. La responsabilidad por el perjuicio ecológico rara vez será ocasionada por una sola persona. Así lo demostró en su oportunidad la Directiva de 2004/35 del Parlamento Europeo y del Consejo, relativa a la responsabilidad medioambiental, al ser impuesta específicamente a profesionales en este ámbito. Así también lo demuestra hoy la Ley francesa del 8 de agosto de 2016, por las condiciones de entidad que el legislador establece respecto del perjuicio ecológico, al impedir, en términos negativos, que éste tenga un carácter "insignificante". ${ }^{32}$ Invariablemente, estos aspectos llevan a analizar el régimen de concursos de intervenciones en materia de responsabilidad extracontractual, donde el Código Civil francés carece de ciertas garantías.

La limitación de la legitimación pasiva en el derecho francés, frente a las personas privadas, se asocia a las restricciones que impone al demandante del perjuicio ecológico para decidir en contra de quien debe dirigir su acción en una hipótesis de coautoría. Deberán en tal caso aplicarse las

32 Artículo 1247 del Código Civil francés. 
reglas de las obligaciones conjuntas, que limitan la libertad de elegir el demandado en el proceso. La única alternativa sería interpretar que el perjuicio resulta susceptible de ser integrado en la teoría de las obligaciones in solidum, aceptada por la Corte de Casación francesa desde 1939, ${ }^{33}$ como limitación del artículo 1310 del Código Civil, que prohíbe presumir la responsabilidad solidaria, exigiendo de una disposición legal, inexistente frente a la responsabilidad civil extracontractual general. No obstante, la aplicación de la teoría de las obligaciones in solidum en el derecho francés requiere de una serie de exigencias, entre las cuales se encuentra la unidad del objeto. Esta unidad no ha sido aceptada por la doctrina frente al perjuicio ecológico (Gueye 2016, 257). La dificultad se asocia a la pluralidad de los componentes integrados en la Ley francesa del 8 de agosto de 2016, en relación con los "elementos de los ecosistemas" y sus "funciones".

Estas limitaciones contrastan con el derecho chileno. Pese a su proximidad al Código Civil francés, la redacción original del Código Civil chileno modificó diferentes aspectos del régimen de responsabilidad civil extracontractual. Entre otros, este fue el caso de las garantías personales favorables a la víctima del delito o cuasidelito civil, en supuestos de coautoría. Aunque el Código Civil chileno conserva el principio del derecho francés, que impide que el intérprete presuma la naturaleza solidaria de las obligaciones, ha modificado su alcance en este ámbito, que ha sido objeto de una disposición específica favorable a la víctima. Así, según el artículo 2317 del Código Civil: "Si un delito o cuasidelito ha sido cometido por dos o más personas, cada una de ellas será solidariamente responsable de todo perjuicio procedente del mismo delito o cuasidelito". La aplicación de esta disposición es amplia. Y, aunque no toda la doctrina califica a la responsabilidad ambiental en términos civiles (Bermúdez 2007, 273), el régimen extracontractual es remitido expresamente. ${ }^{34}$

Por ello, la extensión del derecho chileno, frente a un concurso de autores, recae en las personas en contra de quienes podrá dirigirse el demandante. Así lo impone la articulación de las diferentes legislaciones aplicables a la responsabilidad ambiental. Y es que, si bien esta responsabilidad ha sido consagrada por la Ley 19.300, que carece de codificación, el artí-

33 Sentencia de la Corte de Casación (Cuarta Sala Civil) del 4 de diciembre de 1939, 1941.125.

34 Artículo 51 inciso final de la Ley 19.300.

Esta obra está bajo una Licencia Creative Commons

Atribución-NoComercial-SinDerivar 4.0 Internacional, IIJ-UNAM.

Boletín Mexicano de Derecho Comparado, núm. 158, mayo-agosto de 2020, pp. 733-761. 
culo 51 inciso final de ella, al abrir el régimen de la responsabilidad por el daño ambiental, consagró una remisión particularmente extensa al título XXXV del Libro IV del Código Civil. Esta remisión permite que los artículos 2314 y siguientes del Código Civil, referidos a la responsabilidad civil extracontractual, sean aplicables supletoriamente, en aspectos que no han sido objeto de una disposición especial en la Ley 19.300. Este ha sido el caso de la responsabilidad solidaria ante el concurso de intervinientes en el hecho generador del daño. Por ello, la lectura de la legislación especial y del Código Civil permiten esta aplicación, también con relación a sus causas.

\section{B. El concurso de causas}

A foritiori, ciertas restricciones del derecho francés son el resultado de la dificultad de aplicar la teoría de las obligaciones in solidum frente al perjuicio ecológico. Pese a que tanto las obligaciones solidarias como in solidum son concebidas para la reparación de perjuicios, ellas suponen una afectación indirecta u oblicua de las condiciones de la responsabilidad. La obligación in solidum no sólo permite que el actor se dirija en contra de cualquiera de los intervinientes, sino que también contribuye a determinar su responsabilidad. En particular, desde el punto de vista de la causalidad. Los daños ambientales suelen ser el resultado de múltiples causas, que requieren precisar si ellas suponen una adecuación o una equivalencia. La obligación solidaria contribuye a admitir esta última variante (BelrhaliBernard 2011, 118 y 119), en favor de la reparación del perjuicio. La legitimación pasiva frente al perjuicio ecológico en el derecho francés supone también una restricción en este aspecto.

En efecto, la limitación de unidad de objeto dificulta que la obligación in solidum sea admitida por parte de la Corte de Casación francesa, en relación con el perjuicio ecológico. Esta dificultad tiene una consecuencia procesal inmediata, que impedirá que el legitimado activo pueda dirigirse indistintamente en contra de cualquiera de los coautores en el hecho. Sin embargo, también tiene una consecuencia procesal mediata, al imponer que, de existir dicha pluralidad de intervinientes, el legitimado activo deba acreditar, respecto de cada uno de ellos, una causalidad adecuada a la generación del perjuicio. Este efecto mediato supone la agravación de 
la prueba respecto de la generalidad de intervinientes en el hecho dañoso, relacionada estrechamente con las proyecciones sustantivas de la legitimación. No es difícil imaginar que el actor prefiera ejercer otras acciones, que le permitan conseguir la unidad del objeto, reduciendo el ámbito de la reparación ambiental.

Por contraste, una nueva extensión del derecho chileno, frente a los legitimados pasivos por el daño ambiental, tiene lugar respecto de las exigencias que impone la coautoría para el surgimiento de la responsabilidad. Ya se ha señalado que una obligación de reparación solidaria ha sido consagrada en el artículo 2317 del Código Civil, en materia de responsabilidad extracontractual. Respecto de personas privadas en materia ambiental, esto ha permitido que intervinientes con un grado menor de intervención en el hecho no siempre vean eximida su responsabilidad frente a otro interviniente. Dicha lectura ha sido afirmada en ámbitos diversos, con independencia que las personas privadas actúen entre $\mathrm{si}^{35} \mathrm{o}$ en vinculación con personas públicas, encargada de su vigilancia. ${ }^{36}$ Esto, sin embargo, no debe llevar a desvirtuar las funciones de la responsabilidad. La solidaridad de la obligación a la deuda no se extiende a su contribución, permitiendo que el peso de la reparación se redistribuya a través de la repetición en contra de los restantes, logrando de esta forma equilibrar las responsabilidades que afectan a los diferentes coautores.

\section{CONCLUSIONES}

La consagración de regímenes de responsabilidad por daños ambientales en el derecho chileno y francés ha supuesto diferentes similitudes sustantivas. Sin embargo, también ha conllevado la introducción de considerables variaciones adjetivas, como resultado de las disposiciones legales aplicables y también de la forma en que ellas han sido interpretadas. Un ámbito en el que estas variaciones entre ambos ordenamientos pueden observarse ha sido el régimen de la legitimación que tienen las partes en los procesos de responsabilidad por daños o perjuicios. Las variaciones se observan, ya

\footnotetext{
35 Sentencia de la Corte Suprema del 26 de junio de 2013, rol: 3579-2012.

36 Sentencia de la Corte Suprema del 1o. de septiembre de 2014, rol: 15996-2013 y del 5 de junio de 2016, rol: 3022-2015. 
sea que la legitimación de que se trate adopte un rol activo (referido a los demandantes) o pasivo (con relación a los demandados).

El derecho francés aporta múltiples enseñanzas al derecho chileno en el ámbito de la legitimación activa. Frente a personas públicas, el derecho chileno ha seguido una enumeración taxativa de aquellas competentes para intervenir como demandantes. Aunque esta técnica asegura la intervención del Estado y de las municipalidades, otros órganos descentralizados (funcional o territorialmente) carecen de legitimación. El uso de una enumeración no exhaustiva de personas públicas demandantes en Francia asegura una mejor representatividad de los intereses ambientales, si estos no coinciden con aquellos estatales o municipales (sin condicionar, por lo demás, la legitimación activa al lugar en el que se origina el perjuicio).

Frente a personas privadas, los aportes del derecho francés se reiteran. La interpretación del artículo 54 de la Ley 19.300, respecto de personas que "hayan sufrido el daño o perjuicio" no es unánime en Chile. Mientras que algunos asimilan dicha legitimación a aquella civil, otros la caracterizan en el ámbito medioambiental. Esto se refleja también en la jurisprudencia, afectando la intervención de asociaciones de protección ambiental, que carecen de una legitimación especial en la ley. La técnica empleada en el derecho francés parece más apropiada. Primero, ya que sólo exige un interés (y no un derecho), no siendo susceptible de interpretarse patrimonialmente. Y segundo, ya que otorga una legitimación expresa a estas asociaciones.

En contraste con lo anterior, el derecho chileno aporta diferentes enseñanzas al derecho francés con relación a la legitimación pasiva. Si se trata de personas públicas, el Consejo de Estado francés ha conservado una interpretación restrictiva, que ha impedido que dichas personas sean hasta la fecha objeto de sentencias de reparación del perjuicio ecológico. Si dicho régimen fuera aplicable, la responsabilidad en ámbitos técnicos podría limitar su aplicación, al exigir una falta grave. Todo ello contrasta con el derecho chileno. Por un lado, los tribunales han aceptado tradicionalmente la aplicación de este régimen a la administración. Por el otro, la agravación de grados de culpa no es un aspecto que goce de aceptación en la jurisprudencia, menos aún ante las presunciones de culpabilidad que caracterizan este ámbito.

Frente a personas privadas, los aportes del derecho chileno se reiteran. El derecho francés carece de una disposición específica que consagre un 
régimen de responsabilidad solidaria ante daños ambientales. Si bien esta responsabilidad podría alcanzarse bajo la teoría de las obligaciones in solidum, la reparación del perjuicio ecológico no parece adaptarse a ellas. Esto no sólo limita la reparación en supuestos de coautoría, sino que también impone exigencias en el ámbito de la causalidad, que deberá tener una naturaleza adecuada. El derecho chileno no sólo consagra una disposición que impone la responsabilidad solidaria frente al daño ambiental (artículo 2317 del Código Civil). También ha aceptado que personas con un grado menor de intervención sean responsable, favoreciendo así la equivalencia de condiciones.

\section{BIBLIOGRAFÍA}

AbeLIUK, René. 2001. Las obligaciones. 4a. ed., t. I. Santiago. Editorial Jurídica de Chile.

ANGLÉS, Marisol. 2017. "Algunas vías de acceso a la justicia ambiental". ESQUIVEL, Gerardo et al. Cien ensayos para el centenario de la Constitución Política de los Estados Unidos Mexicanos, t. II. México. UNAM, Instituto de Investigaciones Jurídicas.

Astorga, Eduardo. 2014. Derecho ambiental chileno: parte general, 4a. ed. Santiago. Legalpublishing.

Barros, Enrique. 2006. Tratado de la responsabilidad extracontractual. Santiago. Editorial Jurídica de Chile.

BelRhali-Bernard, Hafida. 2011. "Quand l'obligation in solidum des coauteurs progresse en droit administratif”. Actualité juridique du droit administratif.

BERMúDEZ, Jorge. 2002. "La responsabilidad extracontractual de la administración del Estado por falta de servicio y el daño ambiental". $R e^{-}$ vista de Derecho de la Pontificia Universidad Católica de Valparaíso, núm. 23.

BERMúdEZ, Jorge. 2007. Fundamentos de derecho ambiental. Valparaíso. Ediciones Universitarias de Valparaíso.

BORDALÍ, Andrés. 2010. "Legitimación activa del Estado para demandar la reparación del ambiente dañado y una indemnización de perjuicios (Corte Suprema)". Revista de Derecho (Valdivia), vol. 23, núm. 2. 
BORDALÍ, Andrés. 2018. "Interés legítimo e interés para recurrir en el contencioso administrativo ambiental chileno". Revista de Derecho de la Pontificia Universidad Católica de Valparaíso, núm. 51.

Boutonnet, Mathilde. 2010. "La réparation du préjudice causé à l'environnement". Hokkaido journal of new grobal law and policy, vol. 5.

CalmetTe, Jean-François. 2008. "Le droit de l'environnement: un exemple de conciliation de l'intérêt général et des intérêts économiques particuliers". Revue juridique du droit de l'environnement, núm. 3.

Camproux-Duffrene, Marie-Pierre y Guihal, Dominique. 2013. "Préjudice écologique". Revue juridique de l'environnement, vol. 38, núm. 3.

Camproux-Duffrene, Marie-Pierre. 2015. "La représentation de l'intérêt collectif environnemental devant le juge civil: après l'affaire Erika et avant l'introduction dans le Code civil du dommage causé à l'environnement". CamprouX-Duffrene, Marie-Pierre y SoHnle, Jochen. La représentation de la nature devant le juge: approches comparative et prospective. Vertigo, núm. 22.

Deguergue, Maryse. 2000. "La responsabilité administrative et le principe de précaution". Revue juridique de l'environnement, núm. especial.

Deguergue, Maryse. 2017. "La responsabilité environnementale vue du Droit administratif”. Deguergue, Maryse y Devia, Leila. Responsabilidad ambiental: el derecho francés y comunitario - El derecho argentino y latinoamericano. Buenos Aires. Ediciones Universidad del Salvador.

Delgado, Verónica. 2012. "La responsabilidad civil extracontractual por el daño ambiental causado en la construcción u operación de las carreteras". Revista de Derecho (Valdivia), vol. 25, núm. 1.

DíAZ, Regina. 2007. "Responsabilidad objetiva en el ordenamiento jurídico chileno". Revista de Derecho Universidad Católica del Norte, año 14, núm. 1.

Esteban, Elisabeth y Esteban, Philippe. 2005. "La traducción de la voz legitimación al francés: ¿un concepto de derecho procesal administrativo inexistente en el derecho francés?". Revista de Llengua i Dret, núm. 44.

EveILlaRD, Gweltaz. 2006. "Existe-t-il encore une responsabilité administrative pour faute lourde en matière de police administrative?". Revue française du droit administratif.

Eveno, Nicolas. 2003. La police administrative et le contentieux de l'environnement. Rennes. Tesis doctoral, Universidad de Rennes 1. 
FEMENÍAS, Jorge. 2017. "La culpabilidad en la responsabilidad por daño ambiental y su relación con el sistema de evaluación de impacto ambiental". Revista de Derecho de la Pontificia Universidad Católica de Valparaíso, núm. 48.

FuCHS, Oliver. 2008. "Le régime de prévention et de réparation des atteintes environnementales issu de la loi du ler août 2008". Actualité juridique du droit administratif.

GALDÁMEZ, Liliana. 2017. "Medio ambiente, constitución y tratados en Chile”. Boletin Mexicano de Derecho Comparado, año 49, núm. 148. México, Instituto de Investigaciones Jurídicas.

GARCÍA DE ENTERRÍA, Eduardo. 2000. "Contencioso-administrativo objetivo y contencioso-administrativo subjetivo a finales del siglo XX. Una visión histórica y comparatista". Revista de Administración Pública, núm. 152.

GaUdemet, Yves. 1989. "Le droit administratif en France". Revue internationale de droit comparé, vol. 41, núm. 4.

Gueye, Doro. 2016. Le Préjudice écologique pur. París. Connaissances et savoirs.

Huglo, Christian. 2013. "L’inéluctable prise en compte du dommage écologique par le juge administratif". Actualité juridique du droit administratif.

Huglo, Christian. 2016. "La notion de réparation du préjudice écologique à l'épreuve du droit administratif". Énergie-Environnement - Infrastructures, núm. 11.

Huten, Nicolas y Dumont, Thomas. 2008. "Dommage écologique". Revue juridique de l'environnement, núm. 2.

JÉGOUZO, Yves et al. 2013. Pour la réparation du préjudice écologique. Informe del grupo de trabajo. París, Ministerio de Justicia.

JÉGOUZO, Yves. 2004. "Le juge administratif et l'ordonnancement du droit de l'environnement", Revue juridique de l'environnement, núm. especial.

LARRAIN, Cristián. 2011. "Algunas cuestiones relevantes sobre el derecho al honor y la responsabilidad civil (en particular sobre el daño moral, el artículo 2331 del Código Civil y la legitimación activa)". Revista Chilena de Derecho Privado, núm. 17.

LÉOST, Raymond. 1995. "L'agrément des associations de protection de l'environnement". Revue juridique de l'environnement, núm. 2.

Esta obra está bajo una Licencia Creative Commons

Atribución-NoComercial-SinDerivar 4.0 Internacional, IIJ-UNAM.

Boletín Mexicano de Derecho Comparado, núm. 158, mayo-agosto de 2020, pp. 733-761. 
NESI, Françoise. 2012. "Le préjudice d'atteinte à l'image". BLIND-FranCHOMME, Marie-Pierre. Image(s) E̊ Environnement. Presses de l'Université Toulouse 1 Capitole, LGDJ, Lextenso.

Neyret, Laurent. 2017. "La consécration du préjudice écologique dans le code civil". Recueil Dalloz.

Prieur, Michel. 2011. Droit de l'environnement. 6a. ed. París. Dalloz.

Ramos, René. 1999. De las obligaciones. Santiago. Editorial Jurídica de Chile.

ROPERT, Rodrigo y SAAVEDRA, Rubén. 2005. "La protección del patrimonio cultural en la Ley 19.300, de Bases Generales del Medio Ambiente, a la luz de dos sentencias recientes". Revista de Derecho del Consejo de Defensa de Estado, núm. 11.

Soto KLoss, Eduardo. 2012. Derecho administrativo: temas fundamentales. 3a. ed. Santiago. Legalpublishing.

Sousse, Marcel. 1994. La notion de réparation de dommages en droit administratif français. París, LGDJ.

ThÉvenOt, Jean. 1994. "Environnement et préjudice moral: observations sur les contentieux en réparation". Recueil Dalloz.

TisNÉ, Jorge. 2014. "Los intereses comprometidos en el daño ambiental-comentario al nuevo procedimiento por daño ambiental de la Ley No 20.600". Revista de Derecho de la Universidad Católica del Norte, año 21, núm. 1.

TISNÉ, Jorge. 2016. "Las organizaciones ciudadanas como representantes de intereses colectivos ambientales - Reconocimiento a través de la jurisprudencia chilena". Revista de Derecho de la Pontificia Universidad Católica de Valparaíso, núm. 46.

VAlenZuela, Rafael. 2010. El derecho ambiental: presente y pasado. Santiago. Editorial Jurídica de Chile.

VergarA, Alejandro. 2014. "La tendance actuelle du droit chilien pour une juridiction administrative hyper-spécialisée". BON, Pierre et al. Mélanges en l'honneur de Pierre Bon. París. Dalloz.

VIDAL, Álvaro. 2007. "Las acciones civiles derivadas del daño ambiental en la Ley N 19.300". Revista de Derecho de la Pontificia Universidad Católica de Valparaíso, núm. 29. 